\section{Detección de virus de gripe en sangre donada}

Los virus que causan la gripe, incluido el extremadamente patógeno virus aviar, (H5N1) podrían poner en peligro los bancos de sangre. Cabe recordar que durante el siglo XX hubo tres pandemias gripales (en 1918, la de gripe porcina; en 1957, la de gripe asiática y, en 1968, la llamada gripe de Hong Kong), que hoy día se reconocen como subtipos antigénicos de la gripe A: H1N1, H2N2 y H3N2. Las grandes epidemias de gripe no tienen ningún patrón ni periodicidad previsibles y son muy diferentes una de la otra. Sin embargo, hay datos indicativos de que las verdaderas pandemias, que implican cambios de subtipos en la hemaglutinación, se deben a reagrupamientos genéticos de los virus de la gripe A en animales.

Para comprobar la inocuidad de los abastecimientos de sangre, desde 1997 se ha empleado la técnica de amplificación del número de secuencias del ácido nucleico (TAN) para detectar las hepatitis B y C y el VIH-1 en sangre donada. En 2000, la expansión de la técnica para detectar el virus de la hepatitis A y el parvovirus B19 permitió incluir pruebas para detectar los virus de gripe. El método consistió en mezclar $100 \mu \mathrm{l}$ de hasta 96 muestras y cada mezcla entera de hasta 9,6 ml se centrifugó a $58000 \times g$ durante 60 minutos a $4{ }^{\circ} \mathrm{C}$. Los virus se extrajeron en columnas de espín y el ácido nucleico se eluyó en un volumen de $75 \mu 1$. Para el tamizaje ordinario con este método de amplificación solamente se necesitan $60 \mu \mathrm{l}$ de extracto. El volumen sobrante de $15 \mu l$ puede entonces usarse para tamizaje adicional de los virus de gripe.

La amplificación cuantitativa del virus gripe/H5 se realizó según las instrucciones del fabricante del estuche Artus Influenza/H5 LC RTPCR, QIAGEN, de Hamburgo, Alemania, usando también un termociclador fabricado por Roche en Mannheim, Alemania. La prueba requiere dos reacciones separadas de amplificación. El primer paso es una reacción en cadena de la polimerasa (RCP) genérica de la gripe. La especificidad de esta reacción quedó demostrada con todos los subtipos de gripe A (H1-H15, N1-N9) y todos los subtipos de gripe B. Las muestras que resultaron positivas en la primera RCP se analizaron de nuevo por RCP con cebadores y sondas de la gripe H5N1. Este ensayo permite diferenciar la gripe aviar (H5N1) de otras cepas víricas gripales.
Para remedar la situación de una donación de sangre positiva a $\mathrm{H} 5$, se empleó como estándar de cuantificación externo una cultura sobrenadante depurada de células Vero infectadas con gripe (H5N1) (cepa A/Thailand/1 [KAN-1] 2004). En esta preparación, la integridad de los viriones se confirmó mediante microscopia electrónica. La concentración vírica de ARN se midió en un laboratorio externo mediante múltiples determinaciones simultáneas de la RCP. Se prepararon 10 diluidos con diferentes concentraciones de H5N1 los cuales se añadieron a mezclas séricas negativas de 9,5 $\mu 1$. Esto se hizo ocho veces. Análisis ulteriores de los extractos por medio de reacciones de amplificación genéricas al igual que con virus H5N1 mostraron una probabilidad de detección superior a 95\%.

Los informes de investigadores anteriores indican que, en los Estados Unidos, la TAN descrita ha aumentado la confianza en la inocuidad de los productos sanguíneos. En estudios de la Cruz Roja de Alemania, después de la introducción de esa técnica hubo solamente una transfusión que transmitió el VIH-1. En el estudio aquí descrito se tamizaron 10272 muestras de sangre individuales incluidas en las mezclas y ninguna estaba infectada con gripe, lo que corresponde a un bajo índice $(<20)$ durante el período (febrero a abril de 2006), según el esquema europeo de vigilancia de la gripe. Durante una epidemia se espera un índice de $>80$, como se observó en 2005. Por lo tanto, el tamizaje debe repetirse en cada temporada de gripe. La gripe tiene un período de incubación de 2 a 10 días y es de esperar una fase virémica de infección antes de que empiecen los síntomas clínicos.

Además de poner en cuarentena a los pacientes infectados, tratarlos con medicamentos antivíricos y seguir trabajando hacia una vacuna contra la gripe aviar, durante una pandemia es necesario tamizar a los donantes de sangre para evitar la transfusión de sangre infectada. La TAN puede incorporarse sin demora y el virus puede ser enriquecido suficientemente por centrifugación. Sin embargo, como en todos los métodos que implican mezclas de muestras, la infección podría transmitirse en alguna rara ocasión cuando la viremia del donante estuviera por debajo de la sensibilidad analítica del ensayo de tamizaje. No obstante, hay ciertas estrategias que pueden ponerse en marcha para minimizar esa posibilidad. (Hourfar MK, et al. Blood screening for influenza. Emerg Infect Dis [serial 
on the Internet]. 2007;13(7). Disponible en http// www. cdc.gov/EID/content/1317/1081/htm.)

\section{Fuerte asociación entre el sexo bucogenital y el cáncer faríngeo}

Las personas que durante su vida hayan tenido sexo bucogenital con seis o más parejas tienen muchas más probabilidades de sufrir cáncer faríngeo que otras, sea cual fuere su historia en cuanto al uso de alcohol y tabaco. A esta conclusión llegaron investigadores afiliados a la Escuela de Salud Pública de Johns Hopkins que realizaron un estudio de casos y testigos en el que participaron 100 pacientes recién diagnosticados de cáncer faríngeo - en las amígdalas, base de la lengua y garganta-, y 200 pacientes sin cáncer como testigos. Teniendo en cuenta el trabajo anterior de otros investigadores, el grupo de Johns Hopkins se propuso evaluar la posible relación entre la infección por el papilomavirus humano $(\mathrm{PVH})$ y el carcinoma escamoso de faringe. Se recolectó sangre y saliva de la garganta de los participantes y al combinarlas con moléculas de anticuerpos se pudo determinar si la persona había tenido alguna infección por PVH. Todos completaron una autoentrevista que reveló información sobre su experiencia sexual, incluso el número de personas con quienes habían practicado el sexo bucogenital, así como hábitos de higiene bucal, historial médico, cáncer en la familia, y uso de marihuana, alcohol y tabaco.

Los resultados fueron concluyentes. Haber tenido sexo vaginal con un alto número de parejas ( 26 o más) se asoció con el cáncer estudiado (oportunidad relativa u odds ratio: 3,1; IC95\%: 1,5-6,5), lo mismo que haber tenido sexo bucogenital con 6 o más parejas (OR: 3,4; IC95\%: 1,3-8,8). El grado de asociación aumentó con el número de parejas. El cáncer faríngeo también resultó asociado con la infección bucal por el PVH-16 (OR: 14,6; IC95\%: 6,3$36,6)$, con infecciones bucales por cualquiera de 37 tipos de PVH (OR: 12,3; IC95\%: 5,4-26,4), y con seropositividad a la proteína de la cápside L1 del PVH-16 (OR:32,2; CI95\%: 14,6-71,3). El ADN de PVH-16 se detectó en $72 \%$ de 100 especímenes de tumor preparados en cortes de parafina (IC95\%: 6281) y $64 \%$ de los pacientes con cáncer resultaron seropositivos a la oncoproteína E6 o la E7 o ambas del VPH-16. La seropositividad a la L1 del PVH-16 se asoció con cáncer faríngeo en participantes con antecedentes de un fuerte uso de tabaco y alcohol (OR; 19,4; IC95\%: 3,3-113,9) y entre otros sin esos antecedentes (OR;33,6; IC95\% 13,3-84,8). La relación aumentó también en los pacientes con infección bucal por VIH-16, sea cual fuere su uso de alcohol y tabaco. Por contraste, ese uso aumentó la relación con el cáncer faríngeo principalmente entre los pacientes no expuestos a PVH-16.

Aunque no puede descartarse la transmisión del virus de boca a boca $u$ otra forma desconocida, los resultados de este estudio tienen gran importancia para la salud pública. Desde 1973, en los Estados Unidos ha aumentado la incidencia anual del cáncer de las amígdalas y base de la lengua. La extensa práctica del sexo bucogenital entre los adolescentes puede haber contribuido a ese aumento. De todos modos, es necesario añadir esa práctica sexual a la lista de causas del cáncer de garganta. Además, los datos obtenidos deben alentar al uso de condones durante el sexo bucogenital.

Por otra parte, estos resultados muestran claramente una poderosa razón para que la nueva vacuna Gardasil contra el PVH se administre no solo a las adolescentes, sino también a los varones de esa edad. Cuando en 2006 se aprobó el uso de dicha vacuna, solamente se consideraron las cepas más peligrosas del PVH causantes del cáncer cervicouterino. Por eso la vacuna no se ha recomendado para los varones.

Hasta ahora no ha habido ningún estudio sobre la eficacia de la vacuna para prevenir el cáncer bucofaríngeo. Si la nueva vacuna contra el PVH resultara tan eficaz en la prevención del cáncer bucofaríngeo en ambos sexos como lo es del cáncer cervicouterino, se comprobaría sin lugar a dudas la causalidad entre esa práctica sexual y el cáncer de la lengua y garganta y se buscarían los medios para reconocer a quienes están en riesgo. (D'Souza G, et al. Case-control study of human papillomavirus and oropharyngeal cancer. N Engl J Med. 2007;356: 1944-56.)

\section{Las enfermedades emergentes y los pobres del mundo en desarrollo}

De todas las aflicciones de salud, las enfermedades respiratorias y diarreicas, la tuberculosis y el paludismo tienen el impacto más grande en los pobres del mundo. Sin embargo, en los países de bajos y medianos ingresos, durante los últimos 10 años se ha logrado una disminución notable de las muertes debidas a enfermedades transmisibles. Si esta tendencia continúa, como se espera, la comunidad internacional de salud pública tendrá que concentrar su atención en otros riesgos. En un artículo reciente se expone la hipótesis de que, junto con los avances en el tratamiento de las enfermedades transmisibles, las características del futuro crecimiento de las ciudades determinarán qué problemas de salud ocuparán los 10 lugares más importantes. Hay riesgos emergentes que ya se incluyen entre los de mayor peso por el número de muertes que produ- 